\title{
ADESIVOS DE PRÓTESES REMOVÍVEIS: QUANDO E POR QUE UTILIZÁ-LOS?
}

\author{
Rafaella Tosto Pereira Fonseca Aluna do Curso de Especialização \\ em prótese dentária da Escola \\ Bahiana de Medicina e Saúde \\ Pública.
}

Viviane Maia Oliveira

Doutorado em Clínica Odontológica pela Universidade Estadual de Campinas. Escola Bahiana de Medicina e Saúde Pública e professora doutora da União Metropolitana de Educação e Cultura LTDA.

\section{Emilena Maria Castor Xisto Lima \\ Professora adjunta do Curso de Graduação de Odontologia e da Especialização em Prótese Dentária da Escola Bahiana de Medicina e Saúde Pública.}

\section{Blanca Liliana Torres Leon Escola Bahiana de Medicina e Saúde Pública.}

\begin{abstract}
Resumo
Pacientes submetidos à reabilitação com próteses removíveis esperam que as mesmas possam lhes dar conforto, segurança e quesejam estéticas, devolvendo em parte ou totalmente sua capacidade mastigatória. Estes fatores estão intimamente vinculados aos requisitos funcionais, representados pela retenção, suporte e estabilidade do aparelho protético,porém, em alguns casos essa retenção não ocorre de modo satisfatório, levando o dentista a indicar outros recursos como a utilização de adesivos protéticos, que são substâncias utilizadas para dar uma maior retenção às próteses, que ao absorver água proporcionam uma viscosidade e pegajosidade elevadas, mantendo a prótese em função. Estes adesivos podem ser encontrados na forma de pó, pastas ou fitas adesivas. Apesar da sua extensa utilização, esses materiais ainda são vistos por muitos profissionais de uma forma cética, tendo seu uso relacionado ao "fracasso" na realização da técnica das próteses removíveis.Devido a esta situação controversa, este trabalho teve como objetivo revisar a literatura acerca destes conceitos de adesivos para próteses removíveis, suas indicações, vantagens e desvantagens. Foi possível concluir que os adesivos de prótese removível podem ser indicados em casos de pouca retenção do rebordo, forças musculares excessivas que movimentam a prótese e, principalmente, para o conforto psicológico do paciente.
\end{abstract}

Palavras-chave: Dentadura; Prótese total; Retenção em dentadura.

\section{DENTURE ADHESIVES: WHEN AND WHY USE THEM?}

\begin{abstract}
Patients who are undergoing rehabilitation with removable dentures, hopes that they can give them comfort, safety and that they be aesthetics, returning in part or total their lost chewing ability. These factors are intimately bound to functional requirements represented by the retaining support and stability of the prosthetic device, however, in some cases, the retention does not occur satisfactorily, it is necessary to make use of other resources such as prosthetic use of adhesives which are substances used to give greater retention to the denture. This material may be found in the form of powder, paste or strips, its action occurs when it absorbs water, providing high viscosity and stickiness keeping the prosthesis in function. Despite its extensive use, these materials are still seen by many professionals in an acetic way,
\end{abstract}


and its use related to "failure" in performing the technique of removable dentures. Due to this controversy situation about their use, this article aims to review the literature on these concepts by considering the indications and contraindications to its use. It can be concluded that adhesive can be use when the retention is failure, or the muscle force damaging or to psychological support.

Keywords: Dentures; Complete dentures; Denture retention.

\section{INTRODUÇÃO}

O progresso da Odontologia nos últimos anos é um feito inegável e, desde o início da utilização dos implantes osseointegrados, as possibilidades de tratamento para pacientes total e parcialmente edêntulos se multiplicaram. Os pacientes desdentados totais ou parciais, com grandes reabsorções do rebordo residual e a possível falta de estabilidade das próteses convencionais e/ou a incapacidade psicológica para utilizá-las fazem dos implantes a melhor solução para esses casos.

Existem, porém, situações em que a implantodontia não pode ser utilizada, no caso de pacientes imunodeprimidos, com grandes reabsorções ósseas, patologias tumorais terminais ou mesmo por questões estritamente financeiras. Nesses casos, as próteses removíveis convencionais representam a melhor alternativa de tratamento. ${ }^{(1)}$

A reabilitação bucal com próteses totais (PTs) convencionais evidencia resultados positivos em relação aos índices de impactos bucais; no entanto, é comum o relato pelos usuários dessas próteses com queixasde desconforto, dor, inflamação gengival, limitações funcionais - como mastigação inadequada, instabilidade e falta de retenção - e problemas fonéticos, principalmente nas PTs inferiores. ${ }^{(2)}$ Há, ainda, o fato de que não é incomum encontrarsituações de rebordos alveolares com uma grande reabsorção, resultando em menor suporte para apoiar e manter uma reabilitação convencional com PT, mesmo respeitando todos os passos necessários para confecção da mesma, sendo necessária a utilização de adesivos protéticos para manter essas próteses em função. ${ }^{(3)}$

Os adesivos protéticos foram inicialmente utilizados no final do século XVIII, porém não foram mencionados na literatura odontológica antes de 1935, quando a Associação Odontológica Americana o denominou como não medicinal, junto ao conselho de materiais dentários. A patente mais antiga para "fixador de dentadura" é datada em 1913, tendo em seguida outras em 1920 e $1930 .^{(4)}$ 
Os adesivos para próteses removíveis são utilizados para unir e reter a prótese à área edêntula, sendo amplamente indicados como um auxiliar para aumentar a retenção e estabilidade das próteses.Pesquisas indicam que seu uso reduz significativamente o deslocamento das próteses mandibulares e maxilares durante a mastigação, deglutição e fala. ${ }^{(5)}$

Em 1991, Shay descreveu o mecanismo de ação dos adesivos protéticos que uma vez que aplicado nas próteses, são capazes de manter a prótese em posição através de forças retentivas. Segundo este autor, o volume do adesivo é alterado ao entrar em contato com a água, aumentando de $50 \%$ a $150 \%$ o seu volume, conseguindo preencher o espaço existente entre a prótese e os tecidos. O adesivo absorve a água graças à atração produzida entre os seus ânios e os cátions da mucosa proteica tecidual. Como a saliva aumenta a viscosidade do adesivo, aumenta assim a força necessária requerida para separar a prótese do tecido. ${ }^{(6)}$

Graças a esse efeito de preenchimento, o espaço entre a prótese e o tecido é diminuído, minimizando o acúmulo de partículas de alimentos entre a mucosa oral e a prótese, reduzindo o odor desagradável produzido e uma possível irritação da mucosa devido o acúmulo de alimentos na interface prótese/mucosa. ${ }^{(7)}$

Desta forma, este trabalho tem como objetivo revisar a literatura acerca dos sistemas adesivos protéticos e sua utilização.

\section{REVISÃO DE LITERATURA}

Aumentar a retenção e estabilidade das próteses totais ou parciais é um interesse considerável entre os dentistas protesistas e clínicos. Observando este problema durante o passar dos anos, foram criadas algumas alternativas como as overdentures, implantes e adesivos para próteses removíveis. ${ }^{(8)}$

Em um país em desenvolvimento, tirando como base a situação socioeconômica da grande maioria da população, o uso de implantes muitas vezes torna-se economicamente inviável, desta forma, a prótese removível convencional ainda é considerada o tratamento de escolha da maioria de desdentados no país. O uso de adesivos protéticos para promover uma retenção adequada, nos pacientes que enfrentam problemas de adaptação e/ou retenção da prótese, pode ser uma solução viável. Entretanto, os pacientes devem ser alertados sobre os riscos do uso e do mau uso 
relacionado à utilização destes materiais, para que possa aproveitar o máximo de resultados sem agredir a saúde dos tecidos orais. ${ }^{(9)}$

Para Valle, Godoy e Garcia, o uso de adesivos oferece segurança aos pacientes, tanto física como psicológica, frente ao deslocamento de suas próteses, favorecendo a mastigação. Em contrapartida, alguns pacientes relatam sensações desagradáveis com respeito à textura, odor e sabor. Também com alguns tipos de adesivos, os pacientes tem encontrado dificuldade na utilização. ${ }^{(1)}$

Segundo Tarbet, Boone e Schmidt, os pacientes que fazem uso prolongado de próteses removíveis produzem danos nos tecidos e mucosas de suporte pela pressão contínua exercida sobre o tecido (ósseo e mucoso) e que estes pacientes poderiam se beneficiar do uso dos adesivos, pois a pressão que a prótese exerce com o adesivo no suporte seria menor do que diretamente no tecido e sua distribuição de forças reduz a pressão localizada em um único ponto, dessa forma diminui o trauma que se produz nos tecidos e a irritação na mucosa. ${ }^{(7)}$

As vantagens e desvantagens do uso dos adesivos também são apontadas em trabalhos de autores como Grasso, ${ }^{(10)}$ que defende que os adesivos são um artifício valioso na obtenção de retenção, estabilidade e função mastigatória. Porém ele defende o uso consciente desses materiais, uma vez que existeo riscode mascarar lesões neoplásicas, pois com o crescimento da lesão e a mudança dos tecidos de suporte, pode desadaptar a prótese, dessa forma o paciente faz o uso descontrolado de adesivos para manter a prótese em função, escondendo uma possível lesão carcinogênica.

A mais comum utilização incorreta de adesivos ocorre quando os pacientes que utilizam próteses removíveis por tempo prolongado deveriam refazer ou reembasar estas próteses, por mudanças fisiológicas que ocorre com o tecido de suporte, porém com a facilidade do uso dos adesivos, estes pacientes acabam mantendo em função a prótese inadequada por tempo indeterminado, prejudicando ainda mais o suporte ósseo e mucoso. $^{(10)}$

Discordando de Grasso, ${ }^{(10)}$ no quesito função mastigatória, os estudos de Krishan não sugerem um aumento desta função. No seu estudo foram feitos 576 testes de desempenho mastigatório e 408 testes com 24 indivíduos para determinar e comparar o uso de três tipos de adesivos protéticos, avaliando retenção e habilidade mastigatória. Os três tipos de adesivos mostram um aumento significativo na retenção da prótese nos dois arcos. Já a eficiência mastigatória falhou por não mostrar um aumento 
significativo. Entretanto, o autor relata que alguns pacientes que fazem uso destes adesivos afirmam que estes materiais os ajudam a mastigar melhor, porém os seus testes diferem da opinião destes pacientes, afirmando o autor que estes artefatos podem dar aos que os utiliza uma sensação de segurança e conforto. ${ }^{(11)}$

Estudos mais recentes foram realizados para avaliar a função mastigatória com o uso de adesivos. E, discordando dos estudos previamente realizados por Krishan, ${ }^{(1)}$ Hosegawa, Toshiaki, Hayakawa ${ }^{(12)}$ observam que a função mastigatória com o uso dos materiais adesivos foram positivos.

Neste estudo foi analisado o efeito dos adesivos na estabilidade e função mastigatória de próteses totais, utilizando um sistema 3-D óptico de captura de movimentos, que é capaz de reconhecer múltiplos alvos em movimento e calcular sua coordenada real. Durante o movimento de mastigação, os adesivos aplicados tendem a reduzir os movimentos nas próteses maxilares que utilizaram adesivos. Os adesivos também tenderam a diminuir os movimentos rotacionais e diminuir o tempo de mastigação. Os resultados deste estudo sugerem que os adesivos para dentadura contribuem para reduzir os movimentos das mesmas e melhorar a capacidade mastigatória. $^{(12)}$

Ainda analisando os aspectos referentes à retenção e função mastigatória,Fujimori, Hirano e Hayakaw,também relatam em seus estudos um aumento dessas funções.Neste estudo,o objetivo foi examinar os efeitos dos adesivos na função mastigatória de pacientes desdentados totais, com base na condição de seus tecidos de suporte. O uso dos adesivos para prótese aumentou a força de mordida e teve o desempenho mastigatório elevado, no grupo "pobre" o tempo de mastigação foi diminuído. Dessa forma, este estudo concluiu que o efeito dos adesivos nas funções mastigatórias é positivo para pacientes com um bom tecido de suporte e, principalmente, para pacientes com pouco tecido de suporte. ${ }^{(13)}$

Outro aspecto que ainda deixa dúvidas no uso dos adesivos protéticos é o grau de citotoxidade dos seus componentes, pois este material deveria ser biocompatível, atóxico, e não irritante. ${ }^{(14)}$ Os ingredientes ativos dos adesivos solúveis geralmente incluem polímeros sintéticos (acrílicos, polivinil acético, óxido polietileno, etc.), gomas, pectina, metilcelulosa, hidroximetilcelulose, celulose sódica, agentes antimicrobianos, aditivos, conservantes e corantes. ${ }^{(1)}$ 
Pensando nisso, foram realizados diversos estudos para avaliar o grau de citotoxidade dos adesivos, como,Agarwal et al. ${ }^{(14)}$ Ekstrand, Hensten-Pettersen, ${ }^{(15)}$ Kullmanne Spenciere et al.

Nos estudos de Agarwal et al., foram avaliadas quatro marcas comerciais de adesivos e para testar sua toxidade utilizando macrófagos isolados da cavidade peritoneal de ratos albinos. Todos os adesivos testados mostraram diversos níveis de citotoxidade insatisfatórios. As marcas avaliadas foram:Metrodentpowder, Fixonpowder, Dentiropowder, Fixoncream. ${ }^{(14)}$

Ainda verificando o grau de citotoxidadeEkstrand, Hensten-Pettersen, Kullmanntestaram 19 marcas comerciais, submetendo-as a análise para detectar o grau de citotoxidade e contaminação microbiana, seus resultados apontaram que todos os adesivos para dentadura são citotóxicos e alguns apresentavam contaminação microbiana. Os adesivos com maior grau de contaminação bacteriana foram os "naturais", que continham goma de Karaya, por não conter conservantes na formulação. ${ }^{(15)}$

Gates, Goldschimidt, Kramertambém testaram o grau de contaminação bacteriana em marcas comerciais de adesivos para prótese, e assim como Ekstrand, Hensten-Pettersen, Kullmann, obtiveram resultados positivos. Neste estudo, foram testadas 6 marcas de pó adesivo para análise de contaminação microbiana. $\mathrm{O}$ material foi colocado em placas de petri esterilizadas, contendo uma infusão de cérebro e coração(BHI) e outras amostras em solução de sabouraud's(SAB). Todas as amostras foram incubadas aeróbicamente e anaerobicamente, em 35 graus os que estavam na solução $\mathrm{BHI}$, e 30 graus na solução $\mathrm{SAB}$, durante 2 semanas. Todas as amostras testadas deram positivo para micro-organismos com crescimento bacteriano e fúngico. As amostras foram colocadas no forno de micro-ondas por dez minutos e testadas novamente em seguida. Sete das 24 amostras continuaram a apresentar crescimento de micro-organismos mesmo após ser submetido ao micro-ondas. ${ }^{(16)}$

Grasso ${ }^{10}$ enfatiza que o cirurgião dentista que deve prescrever este material adesivo ao paciente e manter controle do mesmo. Sendo fundamental para maximizar os benefícios de sua utilização e minimizar os seus possíveis efeitos adversos, sendo indicado em casos como próteses totais imediatas, após cirurgias pré-protéticas, suporte psicológico, estruturas anatômicas comprometidas, pacientes que estão utilizando PT pela primeira vez, xerostomia entre outros fatores. Tendo seu uso contraindicado em 
casos de próteses fraturadas, com partes perdidas, quando o dente suporte tiver sido perdido, hiperplasias não diagnosticadas e dificuldades motoras. $\mathrm{O}$ autor ainda lembra que seu uso prolongado deve sempre ser acompanhado por um profissional da área. ${ }^{8}$

Os estudos de Bartlettet al. deixam claro que a utilização dos adesivos podem melhorar a qualidade da alimentação de pacientes portadores de próteses totais convencionais, uma vez que permitem a trituração mais eficiente dos alimentos ingeridos na dieta. ${ }^{(17)}$

\section{CONSIDERAÇÕES FINAIS}

Tradicionalmente, a maioria dos dentistas apresenta uma atitude crítica com relação aos adesivos e, frequentemente, se recusam a indicar os adesivos por considerarem um atestado de falha no tratamento envolvendo o desdentado total. Porém, o uso apropriado e bem indicado dos adesivos pode melhorar a função e a retenção de até mesmo uma prótese com adaptação adequada, além de fornecer uma maior sensação de segurança e conforto ao paciente.

Foi possível concluir que os adesivos de prótese removível podem ser indicados em casos de pouca retenção do rebordo, forças musculares excessivas que movimentam a prótese e, principalmente, para o conforto psicológico do paciente.

\section{REFERÊNCIAS}

1. Valle R, Godoy R.L, Garcia O, Pradies G. Adhesivos para prótesis completas: situaciónactual. RCOE 2007; 12(4): 273-82.

2. Awad M, Jocelyne SF. Measuring patient satisfaction with mandibular prostheses.Community Dentistry and oral Epidemiology. 1998; 26(6): 400-5.

3. Spenciere MCRL, Zavanelli AC, Carvalho Junior H, Zavanelli RA. Impacto $f$ the use of adhesive strip over the satisfaction degree of institutionalized patients and wearers of convencional complete denture. Rev Odonto UNESP. 2009; 38(6): 335-40.

4. Yankel SL. Overview of research and literature on denture adhesives. CompendContinEduc Dent 1984;4(Suppl):518-21.

5. Ghani F, Picton DC, Likeman P R. Some factors affecting retention forces with the use of denture fixatives on vivo. BDJ 1991; 171: 15-21.

6. Shay K. The retention of complete dentures. J Am Dent Assoc 1991;122:70-6. 
7. Tarbet W, Boone M, Schmidt N. Effect of a denture adhesive on complete denture dislodgement during mastication. J Dent1990;4:374-8.

8. Grasso J, Rendell J, GAY T. Effect of denture adhesive on the retention and stability of maxillary dentures. J Dent 1994;72:399-405.

9. Kumar M, Thombare R.U. A comparative analysis of the effect of various denture adhesives available in market on the retentive ability of the maxillary denture: An in vivo study. J Indian prosthodontsoc 2011: 11 (2):82-8

10. Grasso J, MS, DDS. Denture Adhesives. Dent Clin N Am 2004; 48: 721-33

10. Krishan K. A clinical evaluation of denture adhesive. J Dent 1967;6:550-8.

11. Hosegawa S, Toshiaki S, Hayakawa I. Effect of denture adhesive on stability of complete dentures and the masticatory function. J Med Dent Sci 2003; 50: 239-47.

12. Fujimori T, Hirano S, Hayakawa I. Effects of a denture adhesive on masticatory functions for complete denture wearers. J Med Dent Sci 2002; 49: 151-6.

13. Agarwal SK, Praveen G, Gupta S, Tandon R. In vitro evaluation of citotoxicity of dentures adhesives. Indian J Dent Res, 2011;22:526-9.

14. Ekstrand K, Hensten-Pettersen A, Kullmann A. Denture adhesives: cytotoxicity, microbial contamination, and formaldehyde content. J Prosthet Dent 1993;69:314-7.

15. Gates W, Goldschimidt M, Kramer D. Microbial contamination in four commercially available denture adhesives. J Prosthet Dent 1994; 71: 154-8.

16. D.W. Bartlett DW, Maggio B, Targett D,Fenlona MR, Thomas J. A preliminary investigationintotheuse of denture adhesivescombined with dietary advice to improve diets in completedenture wearers. J Dent 2013; 41: 143-7. 